\title{
El neo-liberalismo y la privatización de la economía
}

Aquiles Montoya

\section{Introducción}

Las teorias económicas cuando son auténticas teorias buscan interpretar y explicar una determinada realidad. Ninguna teoría económica puede estar excenta de un contenido ideológico y ello, obviamente, no la invalida. Aunque puede ser más o menos adecuada para dar repuesta a los problemas de la realidad de la cual se ocupa.

Se sabe que el liberalismo surgió como reacción ante los principios mercantilistas, exigido por la realidad particular que presentaba el naciente régimen capitalista. En cambio el neo-liberalismo se presenta como antítesis de la planificación estatal y en tal sentido cuestiona al keynesianismo, por aquello que tiene de intervención del Estado en la actividad económica. El neoliberalismo llega al punto de hacer responsable al Estado de la crisis que presenta el mundo capitalista desde la década de los setenta, olvidando que, precisamente el keynesianismo fue una respuesta ante la crisis de los años 30 .

Independientemente de las objeciones que se le pueden habel hecho al liberalismo, al keynesianismo o al neo-liberalismo importa que nosotros, aqui y ahora, nos percatemos de algo más grave aún, cual es el hecho de que estas teorías han surgido buscando dar respuestas a realidades que no necesariamente tienen que ser idénticas a la nuestra.

Pero en este aspecto, como en muchos otros, hemos sido presas fáciles de las influencias del exterior. Hemos vivido queriendo reproduciı en nuestro país, con varias décadas de atraso, aquellas experiencias que para mayor desgracia nuestra, ya han demostrado su inviabilidac en paises similares al nuestro. 
En El Salvador, como en muchos otros paises del submundo capitalista, necesitamos más que intentar aplicar mecánicamente teorías, o incluso simples ideologlas, conocer nuestra propia realidad, reflexionar sobre nuestra realidad y hacer teoria que de fundamento a la praxis económica.

Ciertamente, no estamos llamando a ignorar todas las teorias existentes, en el proceso de conocimiento no es posible partir de cero. Nuestro llamado es a volver a las fuentes, a ser menos manualescos y conformarnos con simples recetas. Importa evitar caer en el "snobismo"; la teoría económica y las políticas económicas que de ella se derivan son algo demasiado serio como para darnos el lujo de experimentar a costa de la miseria de miles y miles de personas.

Cuando la moda keynesiana se impuso en los paises capitalistas desarrollados, nos vestimos también a la moda aunque con burdas imitaciones y con varios afios de retraso. Ahora, igualmente se nos quieren imponer medidas de política económica de corte neo-liberal y como es la moda, cualquiera otra interpretación de nuestra realidad, sencillamente se mira de reojo como se mira a quien desluce con unos pantalones acampanados.

Pero quienes están a la moda y se limitan a considerar si la liberalización y la privatización de la economia se está efectuando adecuadamente, ¿ya consideraron y reflexionaron acerca de la teoria neoliberal que subyace a tales planteamientos? ¿El neo-liberalismo es en realidad una teoría económica o se reduce a pura ideología? ¿Si es una teoría económica aunque muy cargada ideológicamente comprende y explica nuestra realidad? ¿Los intereses que subyacen a la misma son compatibles con los intereses de las mayorias populares? ¿Son válidos sus supuestos?*

\section{1. ¿Se justlfica la privatlzaclón?}

Uno de los grandes campos donde el neo-liberalismo se está imponiendo $y$ en donde aparentemente posee justificada razón para hacerlo es en la privatización de la actividad económica.

Quienes propugnan por tal retroceso histórico creen haber encontrado suficientes evidencias, apoyadas teórica y prácticamente, en las que consideran "obvias virtudes de la competencia", lo que les lleva

- Véase, por favor, al menos: "El Monetarismo como Ideologla" en Economía de América Latina. CIDE. NN 6 1981; Critica a la Razón Utópica de Franz Heinkelammert; "EI Neo-liberalismo una negación del liberalismo" de Luis de Sebastián. Rev. REALIDAD. Sept./oct./89. 
a sostener que el sector privado puede proveer los servicios públicos con más eficiencia y eficacia que el gobierno, particularmente cuando este posee el monopolio.

En nuestro medio se ha sostenido por muchísimas décadas la tesis de que el gobierno es un pésimo administrador, que los servicios que presta son ineficientes, que existe una excesiva burocracia y últimamente, parecen haber descubierto con asombro que propicia la corrupción y el peculado. Adicionalmente se sef́ala que las empresas estatales no son rentables y que en consecuencia, ello incide negativamente, ya sea generando un déficit público o bien, presionando para que se establezcan mayores cargas tributarias.

El fundamento neo-liberal que está ahora ganando muchos adeptos con su idolatrla por el mercado llega a extremos tales, que quizás al conocerlos haga recapacitar a muchos que dicen estar de acuerdo con la nueva política económica del actual gobierno. Asi tenemos por ejemplo que uno de los vulgarizadores del neo-liberalismo y partidario de la privatización plantea:

"Un grupo de economistas activos, encabezados por los premios Nobel Friedrich A. Hayek y Milton Friedman, afirma que la política monetaria debería de ser forjada por las fuerzas del mercado competitivo y no por los bancos centrales de los gobiernos; en efecto, propone desnacionalizar el dinero, un concepto iconoclata que desafía a una costumbre (recientemente) establecida. El grupo no cuestiona el defrecho del gobierno de emitir dinero, sino su derecho excluslvo de hacerlo y obligar a la gente a usarlo y aceptarlo a un precio determinado. Hayek razona que con otras monedas en circulación, le resultaría más difícil al banco central provocar la inflación del suministro de dinero. La competencia entre los emisores privados de dinero de marca originaría una moneda mejor, al igual que la competencia en otros mercados origina mejores productos. Este es, ciertamente, un provocativo concepto".*

Imagino que tal planteamiento dificilmente podía tener adeptos en nuestro medio entre otras razones porque pretende ignorar una práctica ya superada por su carácter nocivo para la economía.

Adicionalmente los neoliberadores consideran que no se justifican: 
- precios de garantía en la agricultura o regulación de precios agricolas.

- tarifas sobre las importaciones,

- salarios mínimos, como ningún otro control de precios,

- subsidios al transporte,

- control sobre la radio y televisión,

- programas de seguridad social, como los que presta el ISSS, construcción de vivienda por el Estado o subsidio a la construcción de los mismos,

- servicio militar obligatorio; es preciso que se pague un salario suficientemente atractivo para que las personas se alisten voluntariamente, etc.

El análisis de la privatización exige considerarlo desde varios puntos de vista, así tenemos: a) lo que parece ser un mal del Estado mismo; b) las obvias virtudes de la competencia; c) las necesidades de valorización y acumulación del capital y d) los intereses de las mayorías populares.

a) Que el Estado es un mal administrador parece tan obvio que pretender sostener lo contrario resulta una herejía propia de ignorantes o ilusos. Sin embargo, ni el Estado, ni el mercado son sujetos en si mismos. El Estado, a secas, es una simple abstracción personificada que se define por otros elementos, así se habla de un Estado capitalista o de un Estado socialista; a su vez el Estado recibe una concreción mayor en su gobierno, asi podrá ser un gobierno democrático, o un gobierno totalitario. Pero el gobierno se explicita aún mas por el partido que detenta el poder y los partidos por sus principios ideológicospolíticos y los intereses económicos a los cuales representan. $Y$ tales principios o intereses no flotan en el aire sino que se encarnan en seres humanos, de alli que al interior de un mismo partido se observan diferencias que vienen determinadas por la personalidad y el carácter de cada uno de sus miembros.

Por otra parte, si tenemos en cuenta que el presidente Cristiani es un empresario antes que politico, resultaria inconcebible que se negara a si mismo la oportunidad de demostrar que los servicios públicos pueden prestarse con eficiencia y a un mínimo costo.

Por ejemplo, desde una perspectiva social resulta un desperdicio de recursos el tener dos sistemas de correos: uno privado y otro público. Además es claro que el sistema de Correos Nacionales cuenta con mayores recursos humanos y materiales, en consecuencia cuenta con mayores posibilidades para prestar un más eficiente servicio y a un menor costo. ¿Por qué no hacerlo entonces? ¡Ya es tiempo que las 
empresas públicas sean administradas como empresas y por personas capaces. Este es el estilo de gobierno que prometió el Presidente Cristiani y que esperan de él los salvadoreños.

b) Respecto a las obvias virtudes de la competencia, cabe señalar que no son tan obvias como tampoco lo es la competencia, al menos la competencia perfecta, concepto límite 0 ideal al cual pretenden adaptar la realidad los neo-liberales. En nuestro país no es preciso buscar mucho para encontrar que en la mayoría de ramas industriales existe una presencia significativa de empresas monopólicas y oligopólicas.

Ante esta realidad que no es exclusiva de nuestro pais, ni puede serlo, en tanto que es la tendencia "normal" que presenta el desarrollo capitalista, los teóricos llegan a sostener que las empesas monopólicas no son problema si son eficientes, argumento que, obviamente, también puede ser utilizado tratándose de empresas estatales.

En consecuencia lo que debería entenderse es que la realidad no es ni blanca, ni negra y que el problema está mal planeado al considerar como excluyentes: mercado y Estado.

No se puede ni debería sostenerse una sustitución del mércado por el Estado; como tampoco buscar excluir al Estado del mercado.

En una economía mercantil, aún con todas sus imperfecciones, el mercado, cumple una función inestimable. Pero son precisamente sus imperfecciones las que obligan y exigen la participación activa del Estado en la vida económica. Tales son las ineficiencias derivadas de los beneficios y' costos externos; de los bienes públicos; de la inmovilidad de los factores productivos, del conocimiento imperfecto, etc. Por tanto, en nuestro pais, lo que debería de buscarse no es precisamente excluir al Estado, sino por el contrario, lograr su participación de la manera más eficiente posible, ésto, desde una perspectiva económica, desde una perspectiva social nos ocuparemos más adelante.

c) La necesidad de valorización y acumulación del capital.

Nos parece que detrás de los argumentos de la ineficiencia del Estado y las virtudes de la competencia lo que se oculta es la necesidad del capital de ampliar su órbita de valorización y acumulación. Es claro que muchas de las empresas estatales contribuyen a la valorización del capital, pero existen otras que benefician a la mayoria de la población e impiden que el capital lucre a través de ellas o, peor aún, comprimen el beneficio de algún sector capitalista.

La lucha del capital contra las empresas estatales recuerda la lucha 
del capital contra las formas de producción y circulación precapitalista allá en los orígenes del capital en los ahora paises capitalistas desarrollados. En cambio en nuestro medio como imitamos con resago histórico, nos encontramos en los albores del siglo XXI con una realidad excesivamente heterogénea: si bien hegemoniza la producción y circulación capitalista, ello ocurre con la presencia del Estado en la producción y circulación (fenómeno relativamente reciente) y con la pervivencia y proliferación de formas de producción y circulación no capitalistas.

Si realmente deseamos avanzar por la senda del crecimiento económico bajo un esquema capitalista es un sin sentido conservar y multiplicar las formas de producción y circulación no capitalista, las cuales son en si mismas ineficientes en términos de productividad, aunque ello se oculte mediante la prolongación de la jornada y el incremento en la intensidad del trabajo. La atomización de las unidades empresariales es un obstáculo insuperable en cuanto a elevar los niveles de productividad. Tal límite, en cambio, no está presente en las empresas estatales.

En consecuencia si el capital necesita ampliar su campo de valorización y acumulación puede hacerlo a costa de las formas de producción y circulación no capitalistas; con todo, el ingreso medio en estas actividades es generalmente inferior al salario medio en las empresas capitalistas.

La privatización, si bien amplía el campo de valorización y acumulación del capital, viene a agudizar uno de los seculares problemas en nuestro medio, cual es: la concentración estadístico-estructural. Es obvio que quienes tendrán acceso a la actual propiedad estatal serán aquellas fracciones del gran capital, to cual en rigor significaría una mayor centralización del capital. Esto en nada beneficiaría a la sociedad como un todo, en tanto que lo que se estaria efectuando es una redistribución de la riqueza social ya existente y no creando nueva riqueza, con el agravante de eliminar los servicios públicos gratuitos.

Adicionalmente cabría sef̂alar que los precios a los cuales se adquieren las empresas estatales; 0 en general la propiedad estatal, nunca corresponde a su valor real, to cual significa una apropiación privada indebida de una propiedad social, o sea, que la sociedad como un todo está siendo expoliada por una pequeña fracción de la misma. Aunque, acostumbrados como estamos tan solo a la propiedad privada, no nos percatemos del despojo de que estamos siendo víctimas, cuando se privatiza la propiedad estatal, esto es, la propiedad social. 
Si queremos acelerar nuestro crecimiento económico y que éste se traduzca en desarrollo social es preciso hacer eficientes y rentables las empresas estatales y que los empresarios capitalistas reinviertan sus utilidades, esto es, acumulen, ya sea en la producción para la exportación, en sustitución de importaciones o en bienes de consumo básico. O sea, preferentemente, en actividades productivas.

d) Los intereses de las mayorías populares.

La privatización también puede ser analizada desde la perspectiva de los intereses objetivos de las mayorías populares, esto es, en tanto beneficie 0 perjudique a las familias de menores ingresos que constituyen realmente la mayoría de la población.

Para ello bastaria con listar todas aquellas empresas e instituciones públicas que benefician directa o indirectamente a la mayoria de la población y que de acuerdo a los postulados neoliberales son privatizables y deberian privatizarse. Asi tenemos la presencia del Estado en muchas actividades de indole social, tales como: vivienda, salud, educación, recreación, comercialización de productos alimenticios, etc. $O$ en asistencia técnica y crediticia a pequeños productores y comerciantes, etc.

Ciertamente no pretendemos sostener que la forma como el Estado ha manejado estas actividades haya sido eficiente y rentable, pero persistimos en sostener que ello puede superarse y además, que el Estado a diferencia de la empresa capitalista, podria ofrecer productos y servicios de calidad a un mínimo costo, por la sencilla razón de que el móvil del Estado no es, ni debería ser: minimizar costos y maximizar beneficios, sino minimizar costos y minimizar precios. $Y$ ésto es posible tratándose del Estado porque su finalidad es contribuir al bienestar social y no, como el empresario capitalista, maximizar sus utilidades.

Por otra parte, aún suponiendo que el empresario capitalista pueda ofrecer productos y servicios de mayor calidad que los del Estado, en. nada se beneficiaria la mayoría de salvadorehos que no cuentan con los ingresos necesarios para poder comprar tales productos y servicios. Esta es una de las tantas realidades de las cuales no es posible hacer abstracción y que por el contrario es preciso tener muy en cuenta cuando se busca implementar un modelo de economía fundamentado en una teoría que ha sido creada, a partir de y para, una realidad muy diferente a la nuestra.

\section{Refiexión final}

En el desarrollo de este pequeño trabajo hemos buscado evidenciar 
que la privatización de las empresas públicas carece de justificación, ya sea que se argumente que el Estado por definición es un mal administrador o bien que la actividad estatal atenta contra las virtudes de la libre competencia y del omnisapiente y omnipotente nuevo dios: el mercado. Ante bien, creemos haber mostrado que la privatización dentro de un programa de liberalización de la economía únicamente se justifica en orden a crear condiciones que posibiliten una mayor valorización del capital y nuevas oportunidades para la inversión en aquellas actividades que hasta ahora han sido $-y$ deberian seguir siendo- de incumbencia estatal.

Nos parece que, en condiciones como las nuestras, la privatización lejos de aminorar las desequilibrios macroeconómicos y sociales tenderá a exacerbarlos, especialmente por los efectos que inevitablemente tendrá sobre las mayorías populares. Esto, consecuencia de la mayor concentración del ingreso que acarreará el proceso como de la eliminación de los servicios públicos gratuitos y subsidios, que aún con todas sus deficiencias permiten a amplios sectores de la población enfrentar el peso de la crisis.

En consecuencia nos parece que una auténtica salida a los problemas que presentan las empresas e instituciones estatales es aceptar el reto de volverlas eficientes a fin de que no sean una carga para el erario público y puedan a su vez ofrecer bienes y servicios de buena calidad y a bajos precios. Así estarian convirtiéndose en auténticos propiciadores del bienestar social, razón a la cual debería responder su existencia.

Por tanto, no deberá de asombrarnos, ni conducirnos a falsas interpretaciones, el que las mayorías populares opongan una térrea resistencia a la privatización. 